\title{
Evaluation of Immune Dependence of Anthelmintic Treatment of Heligmosomoides polygyrus in CBA/Ca Mice
}

\author{
P. G. FALLON, ${ }^{\dagger}$ J. WARREN $\ddagger$ AND J. M. BEHNKE§ \\ †Department of Pathology, University of Cambridge, Cambridge, CB2 1QP, U.K. \\ $\ddagger$ School of Biological Sciences, University of Wales, Bangor, Gwynedd LL57 2UW, \\ $U . K$ \\ §Department of Life Sciences, University of Nottingham, Nottingham NG7 2RD, \\ U.K.
}

(Received 27 November 1995; accepted 15 February 1996)

\begin{abstract}
Fallon P. G., Warren J. \& Behnke J. M. 1996. Evaluation of immune dependence of anthelmintic treatment of Heligmosomoides polygyrus in CBA/Ca mice. International Journal for Parasitology 26: 557-560. The efficacy of anthelmintic treatment of adult Heligmosomoides polygyrus was evaluated in immunologically intact and immune-incompetent ( $T$-cell-deprived) CBA/Ca mice. There was no statistically significant difference in the cure rate, in terms of percentage reduction in worm burden, following treatment with pyrantel pamoate and levamisole between normal (57-71\% reduction) and immune-incompetent mice (69-78\% reduction). The rate of expulsion, and the total number, of worms expelled from infected mice following drug treatment were comparable in normal and deprived mice. The activity of 2 drugs against adult $H$. polygyrus has been shown to be independent of the immune status of the host. The significance of the mode of actions of drugs and the site of residence of a parasite within the host are discussed.
\end{abstract}

Key words: Heligmosomoides polygyrus; levamisole; pyrantel; immune-dependent chemotherapy.

Experimental studies have shown that the efficacy of chemotherapy of a variety of protozoan and helminth parasitic infections is reduced in immuneincompetent animals. Partial dependence of drug efficacy on the active involvement of the immune system of the parasitized host has been described for Onchocerca volvulus (Bianco et al, 1986), Schistosoma mansoni (Fallon et al, 1992), Trypanosoma brucei rhodesiense (Frommel, 1988), Plasmodium chabaudi (Lwin, Targett \& Doenhoff, 1987), and Leishmania donovani (Iwobi, Doenhoff \& Neal, 1991). The efficacy of drug treatment of a parasitic gastrointestinal nematode in immune-incompetent mice has not, to our knowledge, been evaluated. In this study, the immune dependence of anthelmintic

*To whom correspondence should be addressed. Fax: 01248 371644; E-mail: pfallon@bangor.ac.uk. treatment of a gastrointestinal nematode was tested. Heligmosomoides polygyrus was used as a model murine gastrointestinal nematode (Monroy \& Enriquez, 1992). $H$. polygyrus-infected normal (immunologically intact) and immune-incompetent (T-cell-deprived) mice were treated with pyrantel pamoate and levamisole. Subcurative doses of drug were used; as in previous studies curative doses of drugs killed all parasites irrespective of the immune status of the host. The efficacy of anthelmintic treatment was evaluated by examining the time course of worm expulsion following treatment, and counting the worm recovery at post mortem.

$\mathrm{CBA} / \mathrm{Ca}$ strain mice, originally obtained from Harlan Olac Ltd, Bicester, Oxon, U.K. were bred on site and housed under standard conditions. Agematched male mice were used for all experiments. $H$. polygyrus was maintained in laboratory passage as 
Table 1-Recovery of Heligmosomoides polygyrus from the faeces and intestines of groups of 10 normal and T-cell-deprived mice treated with pyrantel pamoate and levamisole

\begin{tabular}{|c|c|c|c|c|}
\hline $\begin{array}{l}\text { Experimental } \\
\text { Group }^{\mathrm{a}}\end{array}$ & Drug $^{\mathrm{b}}$ & $\begin{array}{l}\text { Mean Worm } \\
\text { Recovery } \pm \text { S.D. }\end{array}$ & $\%$ Reduction $^{d}$ & $\begin{array}{l}\text { Total Faecal } \\
\text { Worms/Mouse } \pm \text { S.D. }\end{array}$ \\
\hline Normal & - & $124.8 \pm 32.9$ & & \\
\hline Normal & PYR & $36.4 \pm 17.5$ & 71 & $96.3 \pm 21.7$ \\
\hline Normal & LEV & $53.7 \pm 15.6$ & 57 & $72.6 \pm 10.4$ \\
\hline Deprived & - & $138.2 \pm 27.3$ & & \\
\hline Deprived & PYR & $42.6 \pm 16.8$ & 69 & $83.8 \pm 24.1$ \\
\hline Deprived & LEV & $31.0 \pm 19.7$ & 78 & $92.3 \pm 13.2$ \\
\hline
\end{tabular}

${ }^{a}$ Normal = immunologically intact mice; deprived $=\mathrm{T}$-cell-deprived mice.

${ }^{\text {bPYR }}=$ Pyrantel pamoate $(5 \mathrm{mg} / \mathrm{kg}) ; \mathrm{LEV}=$ levamisole $(10 \mathrm{mg} / \mathrm{kg})$.

${ }^{\circ}$ Group mean number of worms recovered from intestine at post mortem.

d $\%$ reduction $=$ mean drug - treated group - mean untreated group $\div$ mean untreated group $\times 100$.

'Total number of worms recovered in faeces from each mouse during $24 \mathrm{~h}$ after anthelmintic treatment.

described by Jenkins \& Behnke (1977). Mice were deprived of T-cells by the method of Doenhoff et al. (1981). Briefly, adult male CBA/Ca (4-6 weeks old) were thymectomized and 4 subcutaneous injections of $0.25 \mathrm{~mL}$ rabbit anti-mouse thymocyte serum were given on alternate days. Four weeks were allowed between the last serum injection and the start of experiments. Age-matched normal and T-celldeprived mice were infected orally with $150 \mathrm{H}$. polygyrus $\mathbf{L}_{3}$. Pyrantel pamoate and levamisole were obtained from Sigma (Poole, Dorset, U.K.). Both drugs were administered orally. An aqueous suspension of drug was used, with $0.1 \mathrm{~mL}$ of drug suspension administered per $10 \mathrm{mg}$ body weight. Preliminary experiments involved treatment of infected mice with different doses of drug to establish a subcurative dose of drug, to reduce the worm burden by approximately $80 \%$ or less. Pyrantel $(5 \mathrm{mg} / \mathrm{kg})$ and levamisole $(10 \mathrm{mg} / \mathrm{kg})$ were administered as a single dose 3 weeks after $H$. polygyrus infection.

The expulsion of worms in the faeces after anthelmintic treatment was measured as described by Tanguay \& Scott (1987). The drug-treated and untreated mice were placed in metabolic cages immediately after the drug was administered. Three or four mice were placed in each cage. Moist filter paper was placed on the faecal recovery trap in the metabolic cage. Mice were provided with food and water ad libitum, and were kept in the cages for $24 \mathrm{~h}$ after treatment. The faeces were collected prior to drug treatment and 2, 4, 8 and $24 \mathrm{~h}$ after treatment. The faecal pellets were placed in saline and teased apart, and the number of worms present was counted. The total numbers of worms recovered in the faeces obtained at each time were counted, and expressed as the mean \pm S.D. worms expelled per group. There was a rapid expulsion of worms in the faeces follow- ing drug treatment, with over $70 \%$ of all worms expelled within $4 \mathrm{~h}$ (Fig. 1). There was no difference in the total number of worms expelled for either drug or in the expulsion rate between normal and T-celldeprived mice (Fig. 1, Table 1).

Two weeks after drug treatment the mice were killed under $\mathrm{CO}_{2}$. The gut was removed and placed in saline on a glass Petri dish. The gut was cut longitudinally, and all worms present were removed and counted under a binocular dissecting microscope. The group mean worm recovery \pm 1 S.D. was determined. The Kruskal-Wallis (1-way analysis of variance by ranks) test was used to test for significant differences between groups. There was no significant difference between the recovery of $H$. polygyrus worms in the intestines of untreated normal and deprived mice (Table 1). Drug treatment of normal mice caused a significant $(P<0.001)$ reduction in worm recovery, with a $71 \%$ and $57 \%$ reduction in worms in pyrantel- and levamisole-treated groups, respectively; both drugs effected a comparable 69 $78 \%$ reduction in worm burden in the deprived mice. At the time of post mortem, faecal samples were taken for faecal egg counts. There was no significant difference in the egg production per female between the untreated and drug-treated normal or deprived animals (not shown).

The results indicate that the efficacy of anthelmintics against a model gastrointestinal nematode is independent of the immune status of the parasitized host. If the immune system were to have synergistic activity with the chemotherapy of $H$. polygyrus, it may be expected that the immune effectors that mediate the elimination of $H$. polygyrus would be involved. Thus IgG1 and Th2 cytokinerelated responses (Wahid \& Behnke, 1993; Wahid et al., 1994) would mediate the immune elimination 


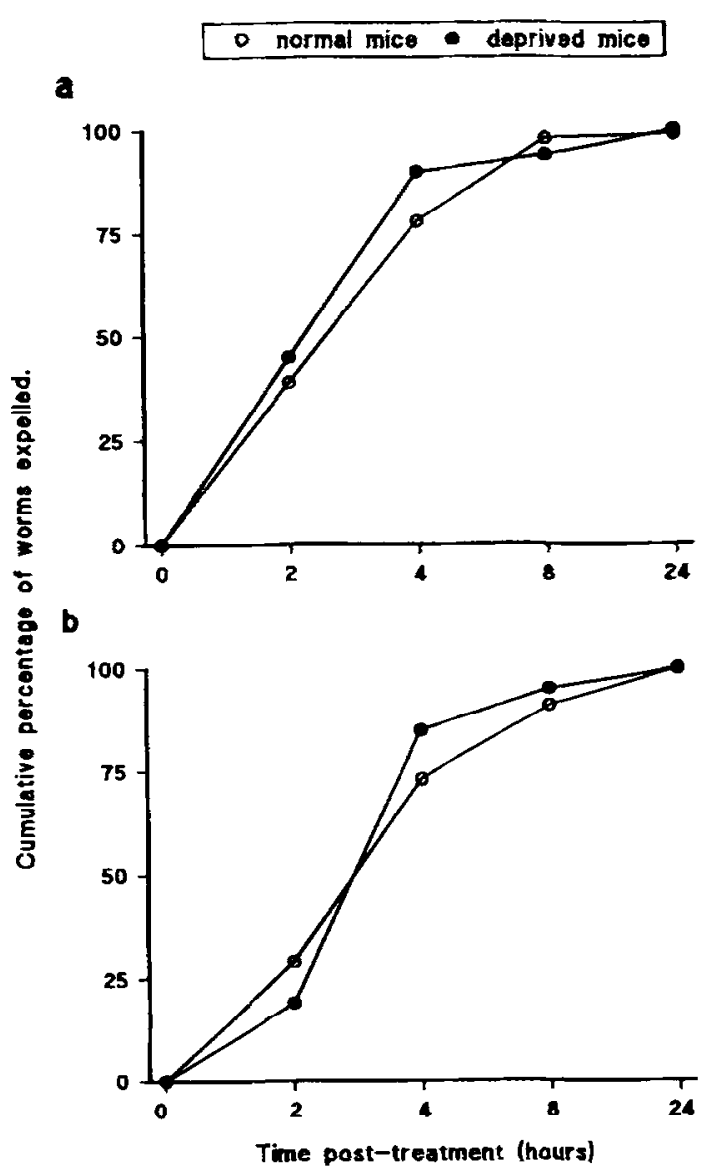

Fig. 1. Cumulative percentage of worms recovered in faeces of Heligmosomoides polygyrus-infected normal and T-cell-deprived mice following treatment with (a) pyrantel pamoate or (b) levamisole. Faecal samples were collected prior to treatment $(0)$ and $2,4,8$ and $24 \mathrm{~h}$ after administration of the drug.

of worms that were treated with drug. We have not examined the effect of $\mathrm{T}$-cell depletion, as performed here by adult thymectomy and adminstration of anti-thymocyte serum, on anti-parasite immunity in $H$. polygyrus-infected mice. However, in T-celldepleted mice infected with $S$. mansoni, non-specific and parasite specific antibody responses, including IgGl, are reduced (Fallon, unpublished results).

The anthelmintics used have different modes of action, but both drugs paralyse nematodes. A consequence of this paralysis is that the parasite is rapidly expelled during the normal peristaltic movement of the gut. Those parasites where the immunity of the host is required for optimum efficacy of chemotherapy are parenteral parasites, either in the circulation ( $P$. chabaudi, $S$, mansoni, $T$. $b$. rhodesiense) or in tissues ( $L$, donovani, $O$. volyulus). For example, drug treatment of the vascular trematode $S$. mansoni with praziquantel also causes immediate paralysis of the worm and a shift of the worm from the mesenteries to the liver. The efficacy of this drug against schistosomes is, however, immune dependent. Following drug-induced hepatic shift the schistosome worm remains accessible, in the hepatic circulation, to immune effector mechanisms including granulocytes and antibodies. Hence, for parenteral parasites there is an opportunity for the host's immunity to interact with the parasites that are damaged by drugs after chemotherapy. In contrast, drug-induced paralysis of parasites that reside in the lumen of the gut causes rapid expulsion of the parasite, as shown here, and the drug-treated parasites are not exposed to the influences of immune effector mechanisms. Studies involving anthelmintic treatment of $H$. polygyrus when the larvae are in the tissue, with a larvicidal drug (ivermectin), may be more appropriate for evaluating the immune dependence of anthelmintic treatment of this parasite. The administration of ivermectins when the parasite is within the intestinal mucosa would permit the direct interaction of mucosal immune responses with the drug-treated larvae.

To conclude, the activity of 2 drugs against adult $H$. polygyrus as a model gastrointestinal nematode was shown to be independent of the immune status of the host. The site of residence of a parasite within the host and the mode of actions of a drug are important considerations when examining the interplay of drugs and host immunity.

Acknowledgements-This work was supported by the Wellcome Trust and the Medical Research Council. We thank Dr Mike Doenhoff for assistance with thymectomies.

\section{REFERENCES}

Bianco A. E., Nwachukwu M. A., Townson S., Doenhoff M. J. \& Muller R. 1986. Evaluation of drugs against microfiliarjae in an inbred mouse model. Tropical Medicine and Parasitology 37: 39-45.

Doenhoff M. J., Pearson S., Dunne D. W., Bickle Q., Lucas S., Bain J., Musallam R. \& Hassounah O. 1981. Immunological control of hepatoxicity and parasite egg excretion in Schistosoma mansoni infections: stage specificity of the reactivity of immune serum in T-cell deprived mice. Transactions of the Royal Society of Tropical Medicine and Hygiene 75: 41-53.

Fallon P. G., Cooper R. O., Probert A. J. \& Doenhoff M. J. 1992. Inmune-dependent chemotherapy of schistosomiasis. Parasitology 105: S4I-S48.

Frommel T. O.,1988. Trypanosoma brucei rhodesiense: effect of immunosuppression on the efficacy of melarsoprol treatment of infected mice. Experimental Parasitology 67: $364-366$. 
Iwobi M. U., Doenhoff M. J. \& Neal R. A. 1991. Immunedependence of chemotherapy of experimental visceral leishmaniasis. Transactions of the Royal Society of Tropical Medicine and Hygiene 85: 56-57.

Jenkins S. N. \& Behnke J. M. 1977. Impairment of primary expulsion of Trichuris muris in mice concurrently infected with Heligmosomoides polygyrus. Parasitology 75: 71-78.

Lwin M., Targett G. A. T. \& Doenhoff M. J. 1987. Reduced efficacy of chemotherapy of Plasmodium chabaudi in T-cell deprived mice. Transactions of the Royal Society of Tropical Medicine and Hygiene 81: 899-902.

Monroy F. G. \& Enriquez F. K. 1992. Heligmosomoides polygyrus: a model for chronic gastrointestinal helminthiasis. Parasitology Today 8: 49-54.
Tanguay G. V. \& Scott M. E. 1987. A technique for determining Heligmosomoides polygyrus (Nematoda) worm burden following anthelmintic treatment in mice. Journal of Parasitology 73: 843-844.

Wahid F. N. \& Behnke J. M. 1993. Immunological relationships during primary infection with Heligmosomoides polygyrus: parasite specific IgGl antibody responses and primary response phenotype. Parasite Immunology 15: 401-413.

Wahid F. N., Behnke J. M., Grencis R. K., Else K. J. \& Ben-Smith A. W. 1994. Immunological relationships during primary infection with Heligmosomoides polygyrus: Th2 cytokines and primary response phenotype. Parasitology 108: 461-471. 